\title{
Peroxisome proliferator activated receptor alpha inhibits hepatocarcinogenesis through mediating NF-KB signaling Pathway
}

\author{
Ning Zhang ${ }^{1,2,3}$, Eagle S.H. Chu ${ }^{1,3}$, Jingwan Zhang ${ }^{1,3}$, Xiaoxing Li ${ }^{1,3}$, Qiaoyi Liang ${ }^{1,3}$, \\ Jie Chen ${ }^{2}$, Minhu Chen' ${ }^{2}$, Narci Teoh ${ }^{4}$, Geoffrey Farrell ${ }^{4}$, Joseph J.Y. Sung ${ }^{1,3}$ and Jun \\ $\mathbf{Y} \mathbf{u}^{1,3}$ \\ ${ }^{1}$ Institute of Digestive Disease and Department of Medicine and Therapeutics, State Key Laboratory of Digestive Disease and \\ Li Ka Shing Institute of Health Sciences, The Chinese University of Hong Kong, Hong Kong SAR, China \\ 2 Department of Gastroenterology, First Affiliated Hospital, Sun Yat-sen University, Guangzhou, China \\ ${ }^{3}$ Gastrointestinal Cancer Biology \& Therapeutics Laboratory, CUHK-Shenzhen Research Institute, Shenzhen, China \\ ${ }^{4}$ Australian National University Medical School at The Canberra Hospital, Canberra, Australia \\ Correspondence to: Jun Yu, email: junyu@cuhk.edu.hk \\ Keywords: PPARa, tumor suppressor, nuclear factor-kappa B, signaling pathway, hepatocellular carcinoma \\ Received: June 16, $2014 \quad$ Accepted: July 11,2014 Published: July 13, 2014
}

This is an open-access article distributed under the terms of the Creative Commons Attribution License, which permits unrestricted use, distribution, and reproduction in any medium, provided the original author and source are credited.

\section{ABSTRACT}

Peroxisome proliferator-activated receptor alpha (PPARa) ligands have been reported to suppress cancer growth. However, the role of PPARa in hepatocarcinogenesis remains unclear. We investigated the functional significance of PPARa in hepatocellular carcinoma (HCC). PPARa-knockout (PPARa ${ }^{-/}$) mice were more susceptible to diethylnitrosamine (DEN)-induced HCC at 6 months compared with wild-type (WT) littermates $(80 \%$ versus $43 \%, P<0.05)$. In resected HCCs, TUNEL-positive apoptotic cells were significantly less in PPARa ${ }^{-1-}$ mice than in WT mice $(P<0.01)$, commensurate with a reduction in cleaved caspase-3 and caspase-7 protein expression. Ki-67 staining showed increased cell proliferation in PPARa ${ }^{-/-}$ mice $(P<0.01)$, with concomitant up-regulation of cyclin-D1 and down-regulation of p15. Moreover, ectopic expression of PPARa in HCC cells significantly suppressed cell proliferation and induced apoptosis. The anti-tumorigenic function of PPARa was mediated via NF-KB as evidenced by inhibition of NF-KB promoter activity, diminution of phosphor-p65, phosphor-p50 and BCL2 levels, and enhancing IkBa protein. Chromatin immunoprecipitation analysis confirmed PPARa directly binds to the IkBa promoter. In conclusion, PPARa deficiency enhances susceptibility to DEN-initiated HCC. PPARa suppresses tumor cell growth by inhibiting cell proliferation and inducing cell apoptosis via direct targeting IKBa and NF-KB signaling pathway.

\section{INTRODUCTION}

Hepatocellular carcinoma (HCC) is the fifth most common solid tumor worldwide and is the second leading cause of cancer-related deaths in China [1,2]. Majority patients with $\mathrm{HCC}$ are diagnosed at an advanced stage with few curable options, and 5-year survival rates are less than $12 \%$ [3]. While those with small HCCs managed by surgical resection, the recurrence rate is up to $50 \%$ at 3 years [4]. Hence, there is pressing need for effective molecular targeted therapies for HCC.
Peroxisome proliferator-activated receptor alpha (PPAR $\alpha$ ) belongs to the nuclear hormone receptor superfamily and plays physiologic roles in energy homeostasis by modulating glucose and lipid metabolism, and transport [5]. PPAR $\alpha$ expression has a major impact on the maintenance of mitochondrial beta-oxidation [6] and has been controversial whether it promotes, or suppresses cancer growth. Several reports describe PPAR $\alpha$ agonists conferring inhibitory effects on cancer cell lines $[7,8]$ and animal models colorectal cancer, ovarian cancer and liver cancer [9-12] in a PPAR $\alpha$-dependent manner [13]. 
Further, PPAR $\alpha$ activated by its agonists acts as a master regulator of inflammation, by suppressing interleukin (IL)-6, TNF- $\alpha$ and NF- $\kappa$ B in the liver $[14,15]$. The antiinflammatory and anti-angiogenic effects of PPAR $\alpha$ also promote the suppression of tumor growth by improving microenvironment. In light of these findings, we propose that PPAR $\alpha$ may act as a potential tumor suppressor against hepatocarcinogenesis. However, HCC has been known to develop when PPAR $\alpha$ agonists are administered long-term to rodents [16]. Thus, elucidating the role of PPAR $\alpha$ whether acting as a tumor promoter or suppressor is important in understanding its contribution to liver carcinogenesis and may provide clues in developing effective treatments against this malignance.

To investigate the effect of PPAR $\alpha$ in hepatocarcinogenesis, we injected PPAR $\alpha$ deficient $\left(\mathrm{PPAR}^{-/-}\right)$and wild-type (WT) mice with diethylnitrosamine (DEN), a carcinogen that is commonly used to induce HCC [17]. Having noted that PPAR $\alpha^{-/-}$ mice were remarkably sensitive to DEN-induced hepatocarcinogenesis, we examined the relationship of PPAR $\alpha$ to the key regulators of cell proliferation and apoptosis in livers from these mice and investigated its tumor suppressive role as well as molecular bases by which PPAR $\alpha$ exerts this function in vitro. We studied PPAR $\alpha$ downstream effectors using cDNA expression array and confirmed that its direct target was NF- $\mathrm{BB}$ by ChIP-PCR. Our findings illustrate that $\operatorname{PPAR} \alpha$ is a potential tumor suppressor in HCC and raise the tantalizing possibility that PPAR $\alpha$ has indeed therapeutic potential in treating this lethal cancer.

\section{RESULTS}

\section{Deletion of PPAR $\alpha$ accelerates DEN-induced liver carcinogenesis}

Fifteen WT mice and PPAR $\alpha^{-/-}$mice were injected with DEN and were examined at 6 and 8 months for the presence of liver tumors (Fig. 1A1). Liver tumors were confirmed as HCC by histology (Fig. 1A2). At 6 month, there was no significant difference in body or liver weights between the two genotypes (data not shown), nor in the macroscopic and histological features of hepatocytes between PPAR $\alpha^{-/}$and WT animals. However, HCCs were identified in $43 \%$ of DEN-injected WT mice and more significantly in $80 \%$ of DEN-injected PPAR $\alpha^{-/-}$animals $(P<0.05)$ (Fig. 1A3). Moreover, tumor quantification was done by counting the macroscopic nodules. We found that the average number of tumors per animal was at least 2-fold higher in PPAR $\alpha^{-/-}$compared to WT mice $(1.47 \pm 0.29$ versus $0.69 \pm 0.24, P<0.05)$ (Fig. 1A4). In contrast to WT mice, tumors were larger in PPAR $\alpha^{-/}$ mice, $42.8 \%$ of HCCs were larger than $2 \mathrm{~mm}$ in DEN- injected PPAR $\alpha^{-/}$mice compared to none in WT animals. Collectively, loss of PPAR $\alpha$ appears to enhance DENinduced hepatocarcinogenesis in mice.

\section{PPARa inhibits proliferation and induces apoptosis in hepatocarcinogenesis}

Proliferative activity in HCCs from PPAR $\alpha^{-/}$and WT mice was determined by Ki-67 immunostaining (Fig. 1B). $\mathrm{HCCs}$ from $\mathrm{PPAR}^{-/-}$mice displayed significantly greater proliferative activity compared to their WT littermates $(22.5 \pm 2.4 \%$ versus $11.0 \pm 1.3 \%, P<0.005)$ (Fig. 1B). Macroscopic tumors from WT littermates and PPAR $\alpha^{-/}$ mice were dissected and used for protein extraction. We then analyzed expression of cell proliferation proteins by western blot, cyclin D1 and p15 in HCCs. Only low levels of cyclin D1 protein were detected in WT HCCs, while increased expression levels were detected in PPAR $\alpha^{-/}$ HCCs. In contrast, p15 protein was greatly decreased in PPAR $\alpha^{-/}$HCCs compared to WT HCCs (Fig. 1D). Further, the apoptotic index was significantly reduced in HCCs from PPAR $\alpha^{-/}$mice compared with WT mice, quantified by TUNEL positive cells $(5.8 \% \pm 0.4 \%$ versus $9.6 \% \pm 0.5 \%, P<0.001$ ) (Fig. 1C). Moreover, apoptotic cell death, assessed by cleaved caspase- 3 and cleaved caspase-7 in HCCs, was diminished in PPAR $\alpha^{-/}$HCCs compared to WT HCCs (Fig. 1D). These findings indicate that the loss of PPAR $\alpha$ in hepatocytes inhibits hepatocyte death and promotes subsequent proliferative activity in $\operatorname{PPAR} \alpha^{-/-}$mice.

\section{PPARa is down-regulated in HCCs and plays a tumor suppressive role in vitro}

We examined the mRNA expression of PPAR $\alpha$ in 27 paired tumor and adjacent normal primary HCC samples and found that PPAR $\alpha$ was markedly down-regulated in tumor tissue compared with adjacent normal tissue $(P<$ 0.001) (Fig. 2A). Downregulation or silence of $P P A R \alpha$ expression was also observed in $5 \mathrm{HCC}$ cell lines, relative to readily expression of PPAR $\alpha$ in normal liver tissue samples (Fig. 2B). We further elucidated whether PPAR $\alpha$ contributes to the growth inhibition of HCC cells. Two HCC cell lines, HepG2 and Huh-7, were stably transfected with PPAR $\alpha /$ pcDNA3.1 or pcDNA3.1 plasmids. Ectopic expression of PPAR $\alpha$ was confirmed in these two HCC cell lines by RT-PCR and western blot (Fig. 2C). Reexpression of PPAR $\alpha$ caused a significant reduction in cell viability in HepG2 $(P<0.01)$ and in Huh-7 cells $(P<0.01)$ (Fig. 2D). The inhibitory effect on HCC cell growth was further confirmed by colony formation assay. There was 30\% reduction in the colonies formed in HepG2 and Huh-7 cells with stable overexpression of PPAR $\alpha$ compared with control cells $(P<0.05)$ (Fig. 2E). These results suggest that $\operatorname{PPAR} \alpha$ exhibits growth inhibitory 
A1

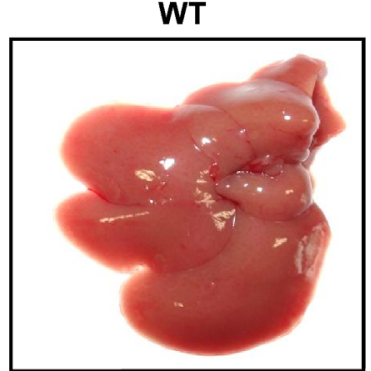

A3

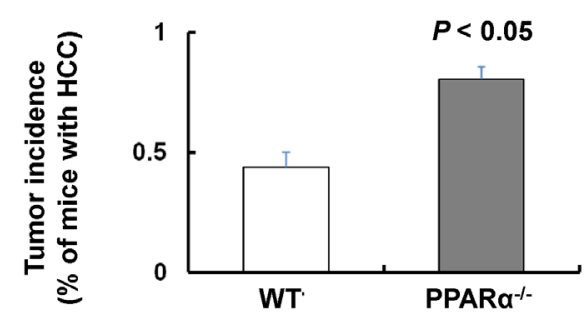

B

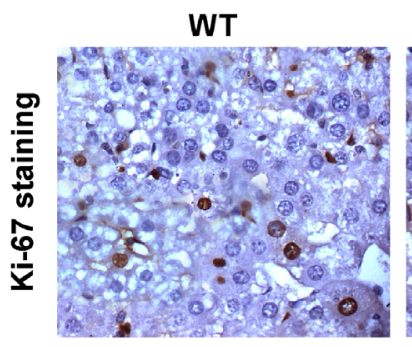

C

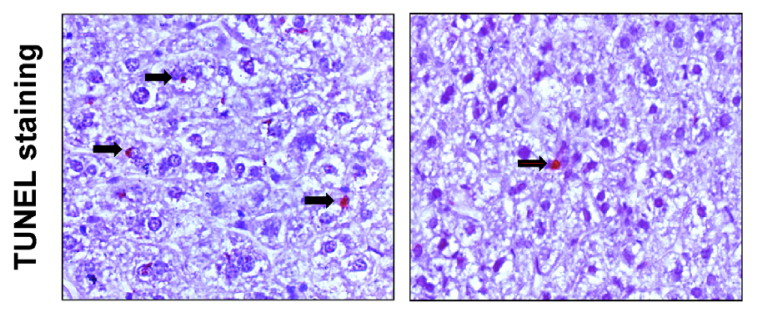

D

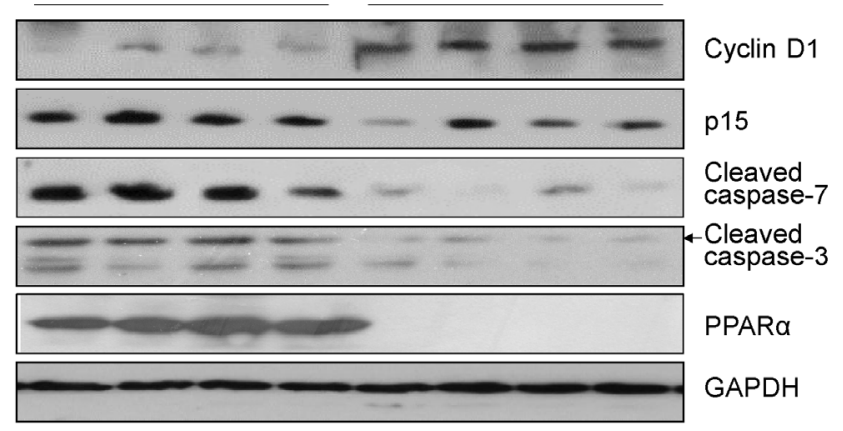

A2

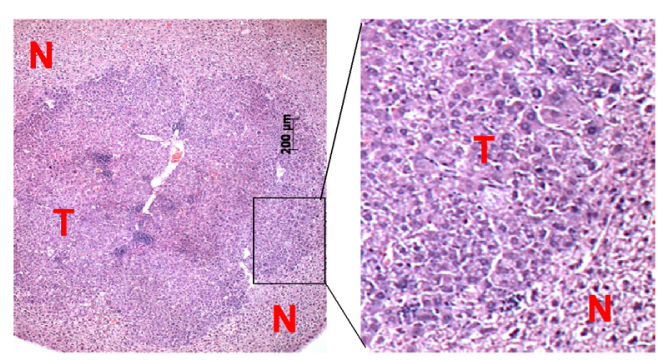

A4

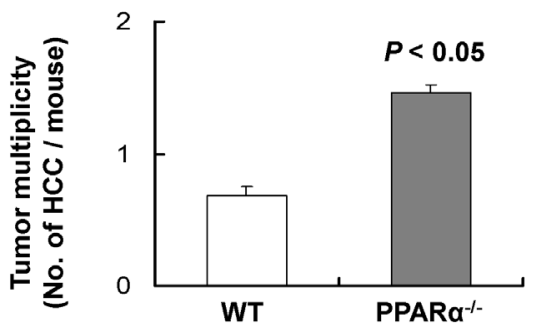

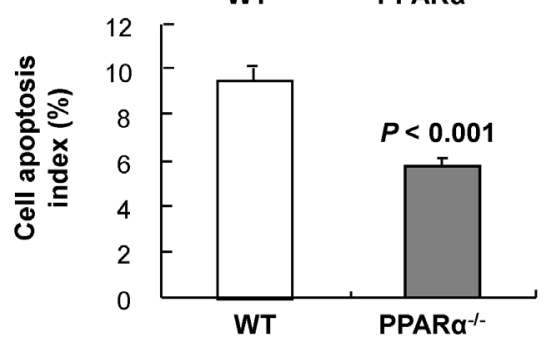

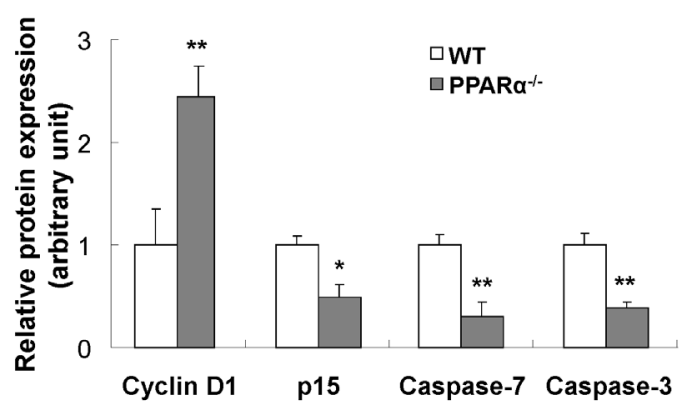

Figure 1: PPAR $\alpha$ loss increases susceptibility to DEN-induced hepatocarcinogenesis. (A1) Gross morphology of typical liver tumors from DEN-treated wild-type (WT) and PPAR $\alpha$ knock out (PPAR $\left.\alpha^{-/}\right)$male mice at 6 months. (A2) Representative microscopic features of HCC in H\&E-stained liver sections of mice. T, tumor; N, adjacent non-tumor tissue. (A3) HCC incidence, and (A4) Number of HCCs per mouse in PPAR $\alpha^{-/}$and WT mice at 6 months were counted and expressed as mean \pm SD, 7-10 mice/group. (B) Cell proliferation in HCCs of PPAR $\alpha^{-/-}$and WT mice by Ki-67 immuno-staining (left panel). Quantitative assessment of cell proliferative index by Ki-67 positive cells (right panel). Data expressed as mean \pm SD, 7-10 mice/group. (C) Apoptosis in HCCs of PPAR ${ }^{-/}$and WT mice by TUNEL staining (left panel). Quantitative assessment of apoptosis determined by TUNEL positive cells (right panel). Data are means \pm SD, 7-10 mice/group. (D) Protein expression of cyclin D1, p15, cleaved caspase-7, cleaved caspase-3 and PPAR $\alpha$ in HCCs from PPAR $\alpha^{-/}$and WT mice determined by western blot. GAPDH was used as a loading control. 
activity in HCC cells.

\section{PPARa effectively induces HCC cell apoptosis in vitro}

In order to ascertain whether apoptosis was responsible for PPAR $\alpha$-induced growth inhibition in vitro, we performed flow cytometry with Annexin V and 7-AAD double staining in HepG2 and Huh7 cells. Our results showed that PPAR $\alpha$ induced a significant increase in the number of early apoptotic cells in both HepG-2 (13.18 \pm $0.30 \%$ vs $8.01 \pm 0.34 \%, P<0.01)$ and Huh-7 $(19.83 \pm$ $0.13 \%$ vs $11.66 \pm 1.16 \%, P<0.01$ ) (Fig. 3A) compared with controls. The induction of cell apoptosis by PPAR $\alpha$ was confirmed by the up-regulation of cleaved caspase-3 and cleaved caspase-7 (Fig. 3B).

\section{PPAR $\alpha$ ablation results in dysregulation of gene expression profiles and signaling pathways in HCCs}

To understand the molecular mechanisms by which PPAR $\alpha$ acts as a tumor suppressive factor in liver tumor development, gene expression microarray was performed in HCCs and non-HCC liver samples from DEN-treated $\mathrm{PPAR}^{-/-}$and WT mice. A total of 1,100 genes were differentially expressed (fold-change $\geq 2$ ) in PPAR $\alpha^{-/}$mice (tumor/normal) compared with WT animals, in which 566 and 544 genes were up-regulated and down-regulated, respectively (Fig. 4A).

We further classified the PPAR $\alpha$-regulated gene candidates according to their biological functions by the Kyoto Encyclopedia of Genes and Genomes (KEGG) pathway analysis using GeneCodis. The results revealed that these genes were mainly enriched in 24 pathways ( $P<0.05, \geq 10$ genes involved in each pathway) (Fig. 4B). Amongst them, 10 major pathways had important functions associated with cell proliferation, apoptosis, migration, and cell-cycle progression including pathways in cancer, MAPK signaling, NF- $\kappa \mathrm{B}$, T cell receptor and chemokine signaling, focal adhesion, adherens junction, cell adhesion molecules (CAMs), cell cycle and Wnt signaling pathway intermediates $(P<0.01)$ (Fig. 4C, $\mathrm{S}$ Table 1). Such data are consistent with previously identified functions of PPAR $\alpha$ in diverse biological processes, which are indicative that the effects of PPAR $\alpha$ inactivation on specific cellular pathways are relevant to cancer development.
A

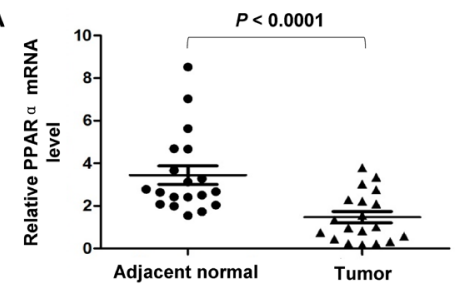

C

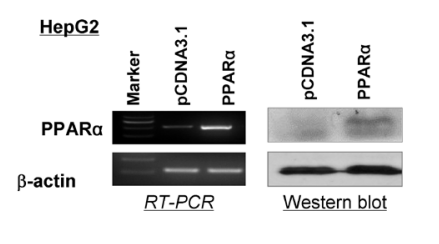

B
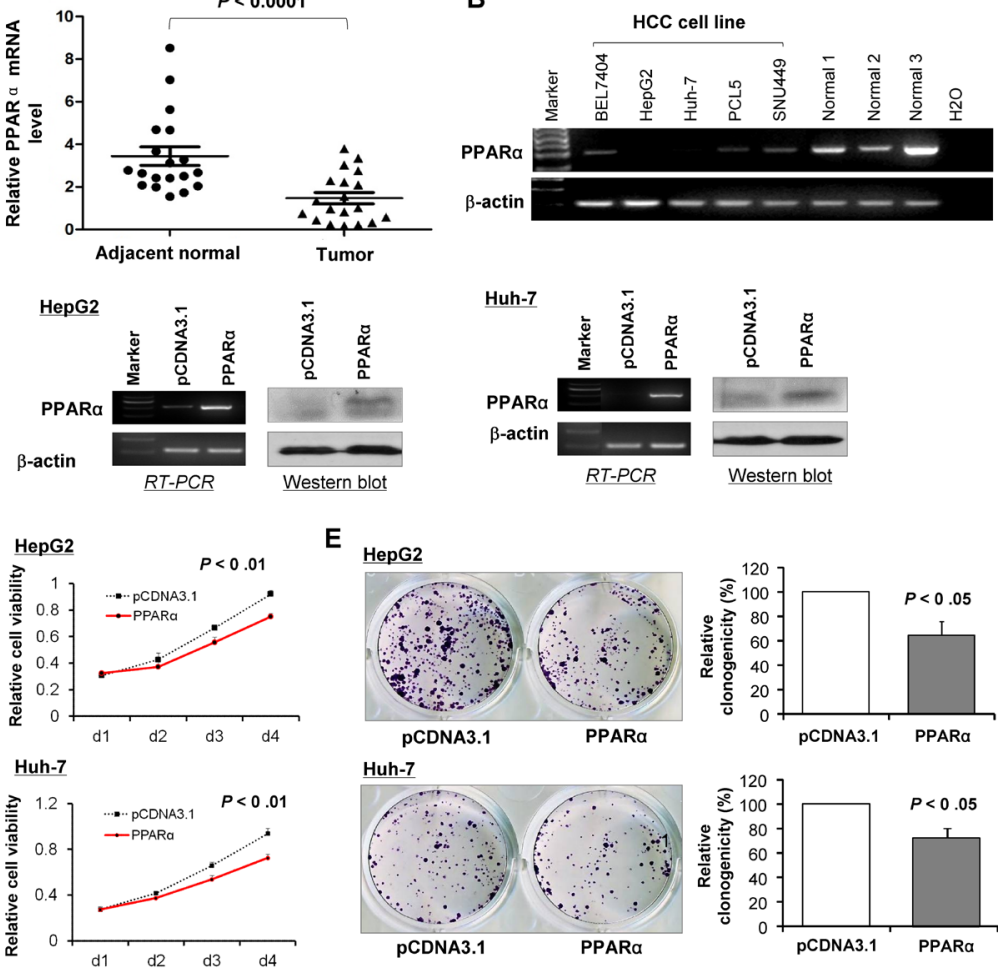

HepG2
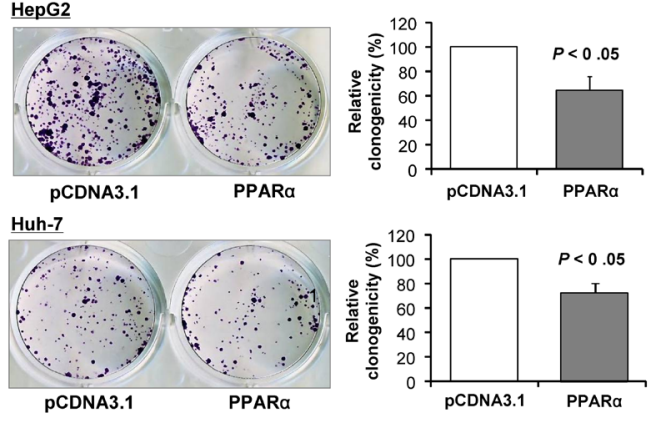

Figure 2: PPAR $\alpha$ is down-regulated in human HCCs and cell lines and its expression suppresses proliferation of HCC cells in vitro. (A) PPAR $\alpha$ mRNA expression is significantly down-regulated in human HCCs compared with their adjacent non-tumor tissue $(\mathrm{n}=27)$ by real-time PCR. (B) PPAR $\alpha$ mRNA expression is silenced or down-regulated in human HCCs cell lines, but readily expressed in normal liver tissue samples. (C) Ectopic expression of PPAR $\alpha$ mRNA and protein in HCC cell lines HepG2 and Huh-7 were evident by RT-PCR and western blot. (D) Ectopic expression of PPAR $\alpha$ suppressed cell viability in HepG2 and Huh-7 cell lines by MTS assay. (E) PPAR $\alpha$ inhibited colony formation in HepG2 and Huh-7 cells. 


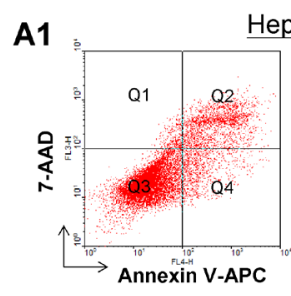

PCDNA3.1

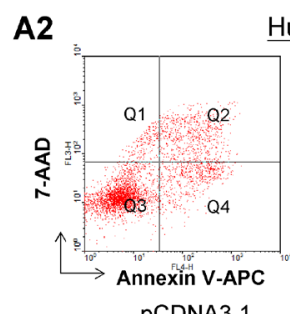

pCDNA3.1

\section{B}

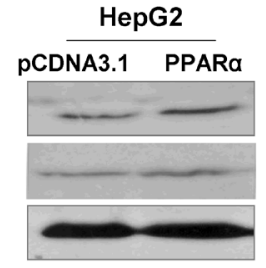

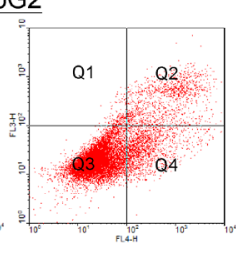

PPAR

Huh-7

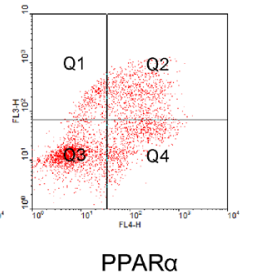

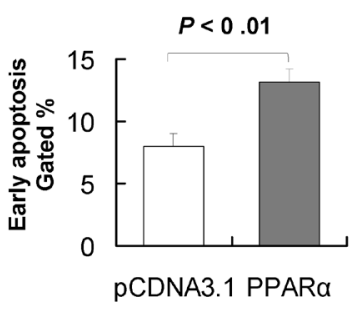

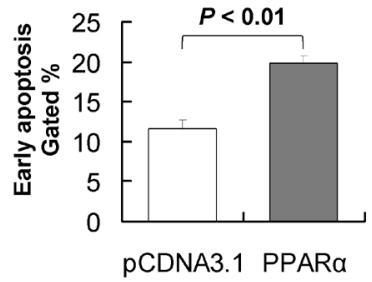

Figure 3: PPARa induces apoptosis of HCC cells in vitro. Hep3B and Huh-7 cells were transfected with pcDNA3.1 or PPAR $\alpha$ for 48 hours; the effect of PPAR $\alpha$ overexpression on apoptosis was determined by FACS and annexin V. Apoptotic cells were significantly increased in PPAR $\alpha$-transfected cells compared with pcDNA3.1-transfected cells, in both HepG2 (A1) and in Huh-7 cell lines (A2). Results are mean \pm SD from experiments performed in triplicate. (B) Protein expression of cleaved caspase-3 and cleaved caspase-7 in Hep3B and Huh-7 cells as evaluated by western blot. GAPDH was used as loading control.
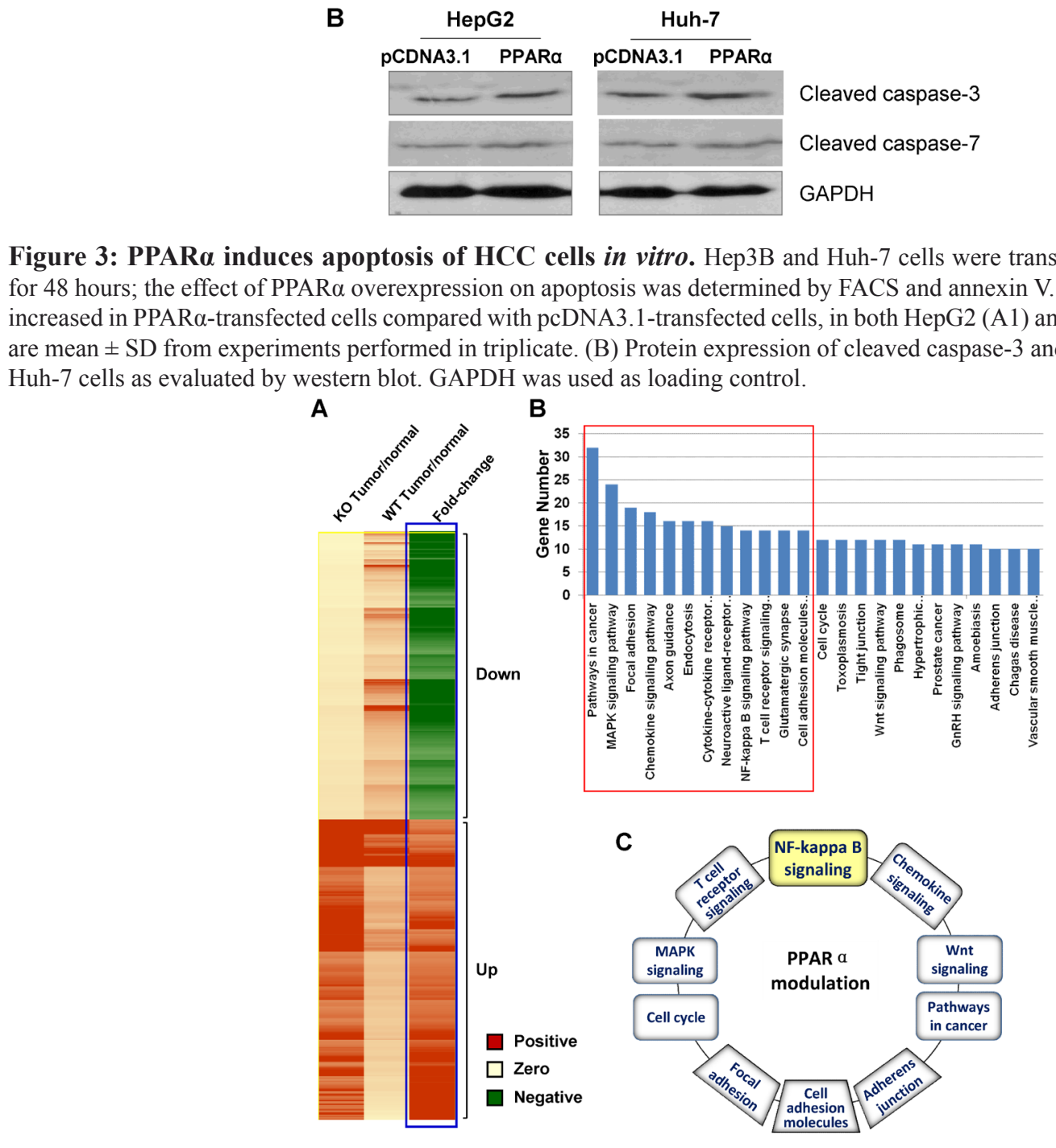

GAPDH

Figure 4: (A) Heatmap illustration of the differentially expressed genes in HCCs of PPAR ${ }^{-/-}$and WT mice by gene expression microarray. A total of 1,100 genes were differentially expressed in PPAR $\alpha^{-/}$mice (tumor/normal) compared with those in WT mice (tumor/normal), with differential expression levels $\geq 2$ (566 genes) or $\leq-2$ (544 genes). (B) KEGG pathway enrichment analysis using GeneCodis (Genecodis version $2.0 \mathrm{http} / /$ genecodis.cnb.csic.es/). A total of 24 pathways were identified to be significantly dysregulated in PPAR $\alpha^{-/}$mice compared with WT mice, with $\geq 10$ genes involved and $P<0.05$. (C) Ten pathways in PPAR $\alpha^{-/}$mice had important functions associated with cell proliferation, cell apoptosis, migration, and cell-cycle regulation. 


\section{PPAR $\alpha$ negatively regulates $\mathrm{NF}-\kappa \mathrm{B}$ signaling}

Notably, the NF- $\mathrm{BB}$ signaling pathway has been reported to be associated with PPAR $\alpha$ [18]. We verified the importance of this pathway under regulation by PPAR $\alpha$ in HCC by in vivo and in vitro experiments. As shown in Fig. $5 \mathrm{~A}$, I $\mathrm{K} \mathrm{B} \alpha$ protein expression, a super suppressor of NF- $\mathrm{KB}$ activation, was significantly decreased in HCCs of $\mathrm{PPAR}^{-/}$mice compared to tumors from WT mice $(P<$ $0.05)$. In contrast, protein expression of the active forms of

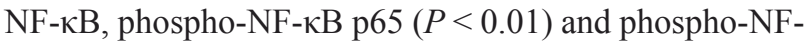
$\kappa \mathrm{B}$ p50 $(P<0.01)$ were significantly enhanced in HCCs of $\mathrm{PPAR}^{-/-}$mice. In keeping with these, NF- $\mathrm{kB}$ activator IL6, and NF- $\mathrm{kB}$ downstream effector B-cell CLL/lymphoma 2 (Bcl2) were up-regulated in PPAR $\alpha^{-/}$HCCs compared with WT HCCs (Fig. 5B).

To further confirm the interaction between the PPAR $\alpha$ and NF- $\kappa \mathrm{B}$ in $\mathrm{HCC}$, we examined the functional effects of PPAR $\alpha$ in NF- $\mathrm{NB}$ in vitro by using an NF- $\mathrm{BB}$ promoter luciferase reporter activity assay and western blot analysis. Transfection of PPAR $\alpha$ significantly decreased NF- $\mathrm{\kappa B}$ promoter luciferase reporter activity in both HepG2 $(P<0.01)$ and Huh-7 $(P<0.01)$ cells, compared with controls (Fig. 5C). Moreover, re-expression

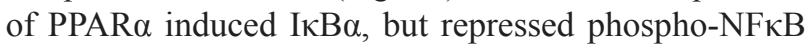
p65 and phospho-NFкB p50 protein expression in both HepG2 and Huh-7 cells by immunobloting (Fig. 5D).

\section{PPAR $\alpha$ functionally interacts with IKB $\alpha$}

To elucidate the key direct effectors of PPAR $\alpha$ in $\mathrm{NF \kappa B}$ signaling, we performed computational prediction of PPAR $\alpha$ binding sites using MatInspector (Genomatix software gmbh, Munich, Germany). Only matrix and core similarity scores of $>0.8$ were considered for the presence of PPAR $\alpha$ binding sites. Interestingly, we identified two conserved regions in the promoter region of $I \kappa B \alpha$ containing PPAR $\alpha$ binding sites (5'-AGGTCA-3') (Fig. $6 \mathrm{~A})$. For validation of direct interaction, we performed ChIP-PCR assay to determine whether PPAR $\alpha$ can bind to the promoter of $I \kappa B \alpha$ gene. Protein isolates from three individual WT mouse livers were immunoprecipitated
A

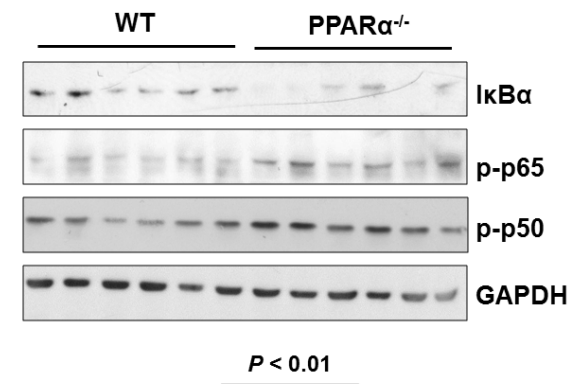

B

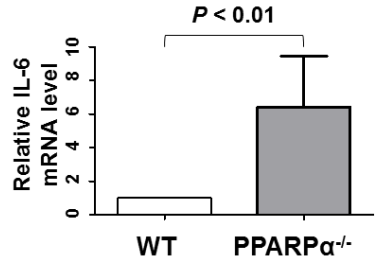

C

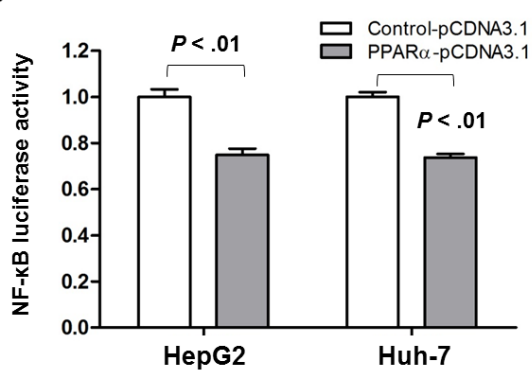

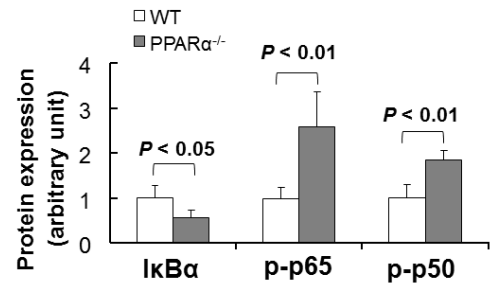

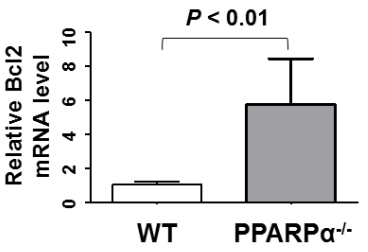

D

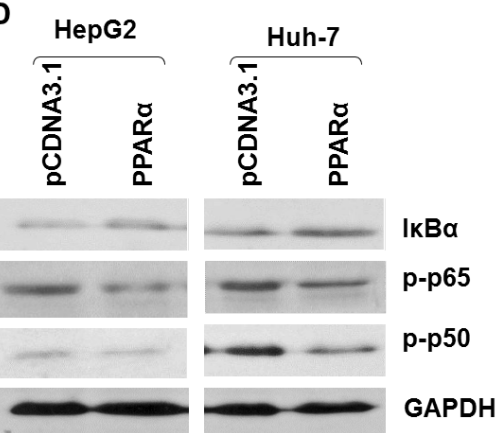

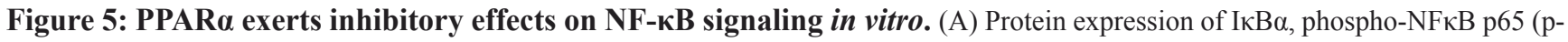
p65) and phospho-NFkB p50 (p-p50) in HCC tissue from PPAR $\alpha^{-/}$and WT mice by western blot. GAPDH was used as loading control. (B) mRNA expression of $B c l 2$ and $I L-6$ in HCC tissues of PPAR $\alpha^{-/-}$and WT mice by real-time PCR. $\beta$-actin was used as an internal control. (C) Luciferase activity was determined by dual luciferase activity assay at 48 hours post transfection with pcDNA3.1 or PPAR $\alpha$ and luciferase plasmids in Hep3B and Huh-7 cells. PPAR $\alpha$ significantly suppressed NF- $\kappa$ B-luc activity. Results expressed are means \pm SD from six

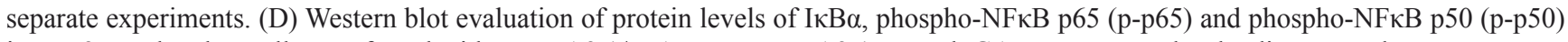
in Hep3B and Huh-7 cells transfected with pcDNA3.1/PPAR $\alpha$ or pcDNA3.1 control. GAPDH was used as loading control. 
with an anti-PPAR $\alpha$ antibody. ChIP-PCR analysis revealed that PPAR $\alpha$ indeed bound to the promoter region of $I \kappa B \alpha$ (Fig. 6B), suggesting a direct protein-DNA interaction between PPAR $\alpha$ and $I \kappa B \alpha$.

\section{DISCUSSION}

Although activation of the PPAR $\alpha$ by its agonists has been shown to inhibit cancer growth including HCC cell lines $[7,19]$, there have been no studies to mechanistically define the role of PPAR $\alpha$ in hepatocarcinogenesis. In this study, we analyzed the role of PPAR $\alpha$ in DEN-induced carcinogenesis using PPAR $\alpha^{-/}$mice. WT as well as $\mathrm{PPAR}^{-/-}$mice did not show spontaneous development of liver tumors up to the age of 6 months. However, in the DEN tumor induction model, loss of PPAR $\alpha$ in mice resulted in a significant increase in HCC development compared to WT animals. Tumor multiplicity was also significantly increased in PPAR $\alpha^{-/-}$mice in comparison to WT mice. Moreover, we observed an increase in cell proliferation by $\mathrm{Ki}-67$ staining and a reduction in cell death by TUNEL staining in the livers of PPAR $\alpha^{-/-}$mice. These results demonstrate that PPAR $\alpha$ deletion induces a more aggressive phenotype of HCC. Thus, this is the first in vivo evidence for an essential role of PPAR $\alpha$ in primary liver cancer development. We also found that PPAR $\alpha$ was down-regulated in human HCCs compared with adjacent non-tumor tissue $(P<0.0001)$ and was silenced or downregulated in all $5 \mathrm{HCC}$ cell lines, further implying that PPAR $\alpha$ may regulate HCC progression with a potential tumor suppressive property.

To further refine the functionality of PPAR $\alpha$ in liver carcinogeness, we analyzed the effect of PPAR $\alpha$ overexpression in two human HCC cell lines, HepG2 and
Huh-7. Ectopic expression of PPAR $\alpha$ led to a significant inhibition of HCC cell viability, and markedly reduced colony formation. Induction of apoptosis in both HepG2 and Huh-7 cells by PPAR $\alpha$ was also observed, with concomitant the increase in protein expression of cleaved caspase- 3 and cleaved caspase-7. Thus, it appears that the growth inhibitory effect of PPAR $\alpha$ is associated with the suppression of cell proliferation and the induction of apoptosis that is mediated in part by activation of the caspase cascade. Our observations also concurrent with recent observations that activation of PPAR $\alpha$ by the PPAR $\alpha$ ligand, clofibrate, in HepG2 cells leads to notable reductions of cell numbers and an induction of apoptosis [19]. Collectively, these findings support an inhibitory role of PPAR $\alpha$ in hepatocarcinogenesis.

To define the molecular basis of HCC development in the absence of PPAR $\alpha$, gene expression microarray analysis was performed to compare the expression profiles between the PPAR $\alpha^{-/}$and WT HCCs. Among the 1,100 differentially expressed genes (fold-change $\geq 2$ ) in PPAR $\alpha^{-/}$mice, KEGG pathway analysis revealed that these candidate genes mainly enriched in 24 pathways, with 10 pathways important in cancer development such as pathways in cancer, MAPK, NF- $\kappa \mathrm{B}$, T cell receptor, chemokine signaling as wells as focal adhesion, adherens junction, cell adhesion molecules (CAMs), cell cycle and Wnt signaling pathway molecules $(P<0.01)$ (Fig. $4 \mathrm{C}$, S Table 1), that regulate cell proliferation, apoptosis, cell-cycle, cell adhesion/metastasis, inflammation and signal transduction in tumors. Many pathways associated with MAPK, Wnt, focal adhesion, chemokine/T cell receptor and cell cycle signaling have been shown to be of significance in HCC [20-22]. These findings further support the functional role of PPAR $\alpha$ in the development
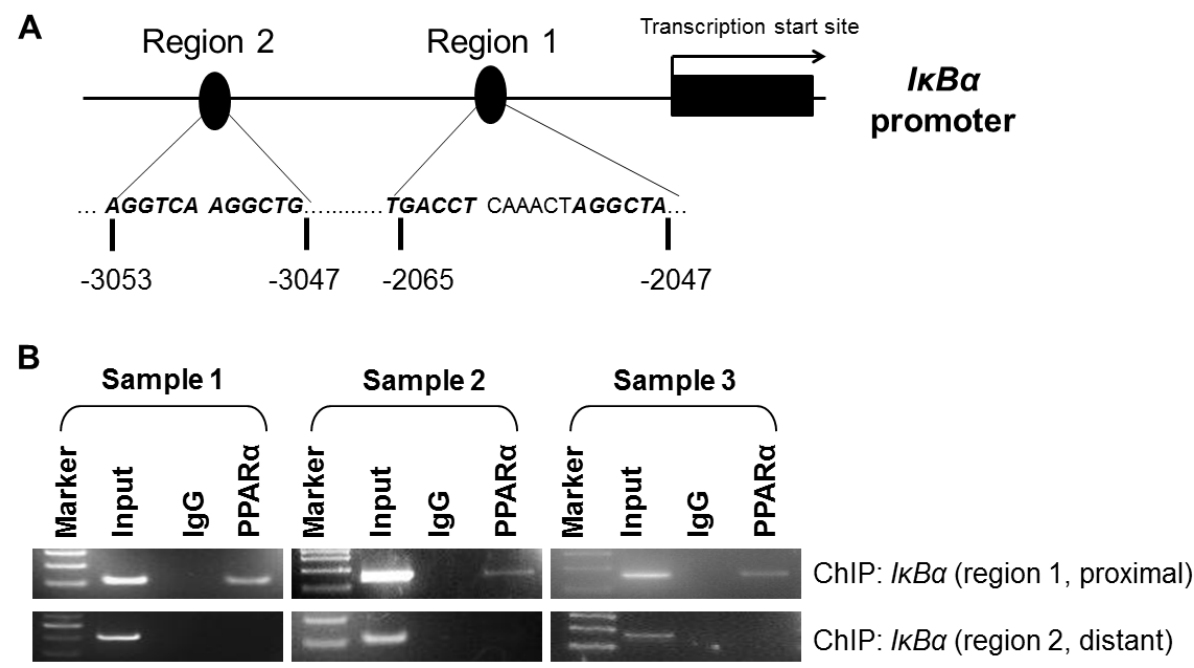

Figure 6: Functional interactions between PPAR $\boldsymbol{\alpha}$ and $\boldsymbol{I} \boldsymbol{\kappa} \boldsymbol{B} \boldsymbol{\alpha}$ promoter. (A) Computational prediction analyses indicate PPAR $\alpha$ binding sites at the promoter region of I $\mathrm{B} \alpha$ gene with two potential regions of PPAR response element (5'-AGGTCA-3'). (B) ChIP-PCR assay reveals that PPAR $\alpha$ binds to the promoter of $I \kappa B \alpha$ gene at the proximal element, but not the distant element. Protein isolates from three individual WT mice livers were immunoprecipitated with anti-PPAR $\alpha$ antibody. ChIP-PCR was subsequently performed to determine the recruitment of PPAR $\alpha$ to the $I \kappa B \alpha$ promoter regions. 
of liver cancer and provide a mechanism for the pro-HCC effects in the context of PPAR $\alpha$ deletion.

The importance of $\mathrm{NF}-\kappa \mathrm{B}$ signaling activation has been well demonstrated in hepatocarcinogenesis [23-25]. The differential activation of NF- $\kappa \mathrm{B}$ in HCCs from PPAR $\alpha^{-/}$mice compared with WT animals may facilitate the cross-talk between hepatocyte and a tumor microenvironment that support tumor growth. NF- $\kappa \mathrm{B}$ activity is tightly controlled at multiple levels by positive and negative regulatory elements. Increased levels of proinflammatory factors such as TNF (S Table 1) and cytokines (e.g. IL-6, Fig. 5B) observed in PPAR $\alpha^{-/-}$mice may plausibly play a role in the differential activation of NF- $\kappa$ B subunits, p65 and p50, in initiating a cascade of NF- $\kappa \mathrm{B}$ activation. This is most likely achieved by phosphorylation and degradation of the I $\mathrm{B}$ protein, a key suppressor of NF- $\mathrm{B}$. Indeed, our data demonstrate increased phosphorylation of p65 and p50, as well as decreased protein expression of $\operatorname{IkB} \alpha$ in PPAR $\alpha^{-/}$mice. Further, a direct interaction between PPAR $\alpha$ and the promoter of $\mathrm{IkB} \alpha$ was demonstrated by ChIP-PCR analysis, inferring that PPAR $\alpha$ controls I $\kappa \mathrm{B} \alpha$ expression through direct PPAR $\alpha$ protein-I $\kappa \mathrm{B} \alpha$ DNA interactions. A similar mechanism has been described by others, that PPAR $\alpha$ inhibits $\mathrm{NF}-\kappa \mathrm{B}$ signaling via the induction of $I \kappa \mathrm{B} \alpha$, although a direct interaction has not yet been clarified definitively between PPAR $\alpha$ and I $\mathrm{B} \alpha$ [26-28].

Active PPAR $\alpha$ binding sites have been identified in the mouse $I \kappa B \alpha$ promoter region $(-2,185$ and $-3,173 \mathrm{bp}$ from transcriptional start site, TSS) and the human $I \kappa B \alpha$ promoter region $(-1,000$ and $-1,795 \mathrm{bp}$ from TSS) [28]. Thus, induction of $I \kappa B \alpha$ is probably the key mechanism of $\mathrm{NF}-\kappa \mathrm{B}$ activation in the PPAR $\alpha^{-/-}$mice. Released NF- $\kappa \mathrm{B}$ p65 and p50 translocate to the nucleus, where they are able to bind the promoter and enhancer regions containing $\kappa \mathrm{B}$ sites, to mediate the transcription of related target genes such as $\mathrm{Bcl} 2$. Bcl2 harbors an NF- $\kappa \mathrm{B}$ binding site in its promoter, which is responsible for the anti-apoptotic activity of NF-кB [29]. Using transient transfection assays, we confirmed that ectopic expression of PPAR $\alpha$ decreases NF- $\kappa$ B promoter activity in two HCC cell lines, with concomitant down-regulatedion of p65 and p50 phosphorylation, and up-regulation of $\mathrm{I} \kappa \mathrm{B} \alpha$. These results further confirm that PPAR $\alpha$ can transcriptionally induce $I \kappa B \alpha$ expression which antagonizes NF- $\kappa \mathrm{B}$ signaling, an observation which is consistent with the critical role for PPAR $\alpha$ in tumor suppression. We and others have previously reported that $\mathrm{PPAR} \alpha$ agonists negatively regulate $\mathrm{NF}-\kappa \mathrm{B}$ signaling in different cellular and animal models [15, 30, 31], implying that PPAR $\alpha$ acts as a possible master inhibitor of NF- $\mathrm{KB}$ activation.

This study strengthens our understanding of how PPAR $\alpha$ mediates hepatocytes proliferation in HCC and provides new mechanistic insights into the importance of PPAR $\alpha$ in inhibiting liver cancer development; one such key pathway is via suppressing NF- $\mathrm{B}$ activation. On the basis of these observations, we propose that strategies involving the enhancement of PPAR $\alpha$ expression in the liver or in combination with current therapeutic regimens may potentially be effective in the management of $\mathrm{HCC}$ in human.

\section{MATERIALS AND METHODS}

\section{Patients and tissues}

Surgically excised HCCs, and surrounding nontumorous liver tissues were obtained from 27 patients at Prince of Wales Hospital, The Chinese University of Hong Kong, Hong Kong. Written consent was obtained prior to surgical resection, and the study was approved by the Human Ethics Committee of The Chinese University of Hong Kong. Tissue collected was immediately snapfrozen and stored in liquid nitrogen for later analyses.

\section{Animals and experimental design}

C57BL/6N PPAR $\alpha^{-/-}$mice were a gift by Professor Geoffrey Farrell (Australian National University Medical School at The Canberra Hospital, Canberra, Australia). Genotyping was performed by polymerase chain reaction (PCR). Male mice at 15 days of age received a single intraperitoneal injection of DEN ( $5 \mathrm{mg} / \mathrm{kg}$ body weight; Sigma Chemical Co., St. Louis, MO) to induce HCC. Mice were sacrificed at 6 months after injection. Livers were excised, weighed, and presence and dimensions of surface HCC nodules were measured. Tumors and nontumorous liver tissue were removed and either fixed in $10 \%$ neutral-buffered formalin or snap frozen in liquid nitrogen. Liver sections from paraffin-embedded blocks were cut and H\&E stained for histologic examination. All experiments in this study were approved by the Animal Experimentation Ethics Committee of the Chinese University of Hong Kong.

\section{Ki-67 staining}

Ki-67 (Abcam, Cambridge, UK) was detected in paraffin-embedded liver sections of mice using an avidin-biotin complex immunoperoxidase method. The proliferation index was determined by counting the numbers of positive staining cells for $\mathrm{Ki}-67$ as a percentage of the total number of cells. At least 1000 cells were counted each time. 


\section{Terminal deoxynucleotidyl transferase-mediated nick-end labeling (TUNEL) staining}

TUNEL staining was employed for detection of apoptosis in liver sections (Promega, Madison, WI). The apoptosis index was calculated as a percentage of TUNEL-positive cells showing unambiguous brown nuclear staining $(\mathrm{n}>1000)$.

\section{Human HCC cell lines and culture}

The human HCC cell lines (BEL7404, Hep G2, Huh-7, PLC5, SNU449) were obtained from the American Type Culture Collection (ATCC, Manassas, VA). These cell lines were cultured in Dulbecco's modified Eagle medium with $10 \%$ fetal bovine serum (Gibco BRL, Rockville, MD), and maintained at $37^{\circ} \mathrm{C}$ in a humidified incubator with $5 \% \mathrm{CO}_{2}$.

\section{Construction and transfection of PPARa expression vector}

The entire coding sequence of human PPAR $\alpha$ cDNA was cloned and inserted into the pcDNA3.1 vector. HCC cell lines Hep G2 and Huh-7 were transfected with pcDNA3.1-PPAR $\alpha$ or pcDNA3.1 control plasmid using Lipofectamine 2000 (Invitrogen, Carlsbad, CA). Cells were collected for analyses at $48 \mathrm{~h}$ after transfection.

\section{Colony formation assay}

After transfection, cells were collected and seeded $\left(3 \times 10^{3} /\right.$ well) in 6-well plates for 14 days. Colonies $(\geq 50$ cells/colony) were counted after fixed with $70 \%$ ethanol and stained with crystal violet solution.

\section{Cell viability assay}

This was determined by 3-(4, 5-dimethylthiazol2-yl)-5-(3-carboxymethoxyphenyl)-2-(4-sulfophenyl)2H-tetrazolium (MTS) assay (Promega, Madison, WI). Briefly, $3 \times 10^{3}$ cells/well was seeded in 96-well plates. $20 \mu \mathrm{l}$ of reaction solution containing $333 \mu \mathrm{g} / \mathrm{ml}$ MTS and $25 \mu \mathrm{M}$ phenazine ethosulfate was added to culture cells in $100 \mu \mathrm{l}$ culture medium every $24 \mathrm{~h}$ and incubated at $37^{\circ} \mathrm{C}$ for 1 hours. Cell viability was measured as an optical value of the mixture (wave length of $490 \mathrm{~nm}$ ).

\section{Cell apoptosis assay}

Apoptosis was also measured by staining cells with Annexin V (APC-conjugated) and 7-amino-actinomycin
(7-AAD) (BD Biosciences, San Jose, CA), then analyzed by fluorescence-activated cell sorting (FACScan, BD, Franklin Lakes, NJ). Cell populations were classified as viable (Annexin V-negative, 7-AAD-negative), early apoptotic (Annexin V-positive, 7-AAD-negative), late apoptotic (Annexin V-positive, 7-AAD-positive), or necrotic (Annexin V-negative, 7-AAD-positive).

\section{Western blot analysis}

Total protein was extracted and protein concentration was measured by the method of DC protein assay Bradford (Bio-Rad, Hercules, CA). Thirty $\mu \mathrm{g}$ protein from each sample was separated on Tris-polyacrylamide gel by electrophoresis and blotted onto nitrocellulose membranes (GE Healthcare, Piscataway, NJ). Membranes were incubated with primary antibodies overnight at $4{ }^{\circ} \mathrm{C}$ and an appropriate secondary antibody for 1 hour at room temperature. Primary antibodies used were: anti-cyclin D1 (sc-8396), anti-IкB $\alpha$ (sc-847), anti-phospho-NFкB p50 (sc-271908), anti-phospho-NFkB p65 (sc-8008) and antiGAPDH (sc-365062) (Santa Cruz Biotechnology, Santa Cruz, CA); anti-p15 (ab53034) and anti-PPAR $\alpha$ (ab97609) (Abcam); anti-Cleaved caspase-7 (\#9491), anti-Cleaved caspase-3 (\#9661) (Cell Signalling Technology, Danvers, MA). Proteins were visualized using ECL Plus Western blotting Detection Reagents (GE Healthcare, Piscataway, NJ).

\section{cDNA synthesis and RT-PCR}

Total RNA was extracted from liver tissue and cell pellets using Qiazol reagent (Qiagen, Valencia, CA). Total RNA was reverse-transcribed by High Capacity cDNA Reverse Transcription Kit (Invitrogen). Semi-quantitative RT-PCR was performed using Hot-start DNA polymerase (Invitrogen). And real-time PCR was performed using SYBR Green master mixture (Applied Biosystems) on HT7900 system (Applied Biosystems, Foster City, CA).

\section{Gene expression microarray analysis}

Gene expression profiles of HCCs and adjacent normal liver tissues from two pairs samples of PPAR $\alpha^{-/-}$ and WT mice were analyzed using Whole Mouse Genome Microarray Kit, 4x44K (Agilent Technologies, Palo Alto, CA), which contained 43,379 cDNA clones. In brief, RNA was extracted using Qiazol reagent (Qiagen, Valencia, CA). The cDNA probes were prepared from $5 \mu \mathrm{g}$ of total RNA labeled with Cy5-dUTP (red) or Cy3-dUTP (green) by reverse transcription (Amersham Biosciences, Piscataway, NJ). Two labeled cDNAs were competitively hybridized to the microarray. Signal intensities were analyzed using a GenePix 4000A scanner (Axon 
Instruments, Molecular Devices Crop., Palo Alto, CA). Array data were presented as log base 2 ratio of the $\mathrm{Cy} 5 /$ Cy3 signals. Gene expression patterns between HCCs and controls were analyzed using unsupervised hierarchical clustering.

\section{Dual-Luciferase reporter activity assay}

Luciferase reporter activity of NF-кB-luc (5xNF$\kappa \mathrm{B}$ binding sites) was examined. HCC cells were cotransfected with NF-KB-luc (195 ng/ well), pRL-CMV vector $(5 \mathrm{ng} /$ well), and pcDNA3.1 or PPAR $\alpha$ plasmid (200 ng/ well). Cells were analysed at 48 hours after transfection, and the ratio of firefly to renilla luciferase activity was analyzed by the dual-luciferase reporter assay system (Promega).

\section{Chromatin immunoprecipitation (ChIP)}

ChIP assay was performed on liver tissues from DEN-treated PPAR $\alpha^{-/-}$and WT mice using EZ-Magna ChIP A kit (Millipore, Billerica, MA). Chromatin DNA fragments were precipitated with $10 \mu \mathrm{g}$ anti-PPAR $\alpha$ antibody (ab97609) (Abcam, Cambridge, MA). DNA was then de-cross linked and extracted from the DNA-protein complex. Immunoprecipitated DNA was subjected to ChIP-PCR validation. Distant ChIP-PCR primers are as follows: 5'-GGCACAGTGTCGGACGATT-3' (forward) and 5'-GCTTCAGTTTTCTCCTCATTGTCAA-3' (reverse). The proximal primers are 5'-CCCAAGCGGAAGACAGATT-3' (forward) and 5'-GTAAAGTATATGTTAACCCTTGGAA-3' (reverse).

\section{Statistics}

Statistical analysis was performed using the SPSS statistical software package (standard version 13.0, SPSS Inc., Chicago, IL). Data were expressed as mean \pm standard deviation (SD) with $P<0.05$ considered as statistically significant.

\section{Conflict of Interest}

There is no conflict interest.

\section{Abbreviations}

$\begin{aligned} & \text { Bcl2, B-cell CLL/lymphoma 2; } \\ & \text { complementary DNA, }\end{aligned}$ ChIP, chromatin
immunoprecipitation; DEN, diethylnitrosamine;
ERK, extracellular signal regulated kinase; GAPDH,
glyceraldehyde-3-phosphate dehydrogenase; HCC,
hepatocellular carcinoma; H\&E, hematoxylin and eosin;

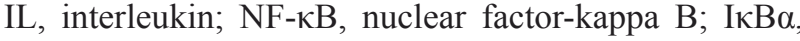
NF-кB inhibitor alpha; JAK/STAT, Janus kinase/signal transducer and activator of transcription; MAPK, mitogenactivated protein kinase; PCR, polymerase chain reaction; PPARs, peroxisome proliferator-activated receptors; PPREs, peroxisome proliferator response elements; TUNEL, terminal deoxynucleotidyl transferase-mediated nick-end labelling; WT, wild-type; KO, knockout; PPAR $\alpha^{-/}$, PPAR $\alpha$-knockout; KEGG, Kyoto Encyclopedia of Genes and Genomes.

\section{Financial Support}

The project was supported by Theme-based Research Scheme of the Hong Kong Research Grants Council (T12-403-11); National Basic Research Program of China (973 Program, 2013CB531401); Collaborative Research Fund (CUHK/CRF/09; CUHK3/CRF/12R; HKU3/CRF11R) of the Research Grant Council Hong Kong; CUHK Focused Investments Scheme B and Shenzhen Virtual University Park Support Scheme to CUHK Shenzhen Research Institute.

\section{REFERENCES}

1. El-Serag HB and Rudolph KL. Hepatocellular carcinoma: epidemiology and molecular carcinogenesis. Gastroenterology. 2007; 132: 2557-76.

2. Thomas MB, Jaffe D, Choti MM, Belghiti J, Curley S, Fong Y, Gores G, Kerlan R, Merle P, O’Neil B, Poon R, Schwartz L, Tepper J, et al. Hepatocellular carcinoma: consensus recommendations of the National Cancer Institute Clinical Trials Planning Meeting. J Clin Oncol. 2010; 28: 39944005.

3. El-Serag HB. Hepatocellular carcinoma. N Engl J Med. 2011; 365: 1118-27.

4. Shah SA, Cleary SP, Wei AC, Yang I, Taylor BR, Hemming AW, Langer B, Grant DR, Greig PD, Gallinger $\mathrm{S}$. Recurrence after liver resection for hepatocellular carcinoma: risk factors, treatment, and outcomes. Surgery. 2007; 141: 330-9.

5. Lefebvre P, Chinetti G, Fruchart JC, Staels B. Sorting out the roles of PPAR alpha in energy metabolism and vascular homeostasis. J Clin Invest. 2006; 116: 571-80.

6. Aoyama T, Peters JM, Iritani N, Nakajima T, Furihata K, Hashimoto T, Gonzalez FJ. Altered constitutive expression of fatty acid-metabolizing enzymes in mice lacking the peroxisome proliferator-activated receptor alpha (PPARalpha). J Biol Chem. 1998; 273: 5678-84.

7. Panigrahy D, Kaipainen A, Huang S, Butterfield CE, Barnés CM, Fannon M, Laforme AM, Chaponis DM, Folkman J, Kieran MW. PPARalpha agonist fenofibrate suppresses tumor growth through direct and indirect angiogenesis inhibition. Proc Natl Acad Sci U S A. 2008; 105: 985-90. 
8. Marina M, Manuela O, Giuliana M, Canuto RA. Involvement of PPAR $\alpha$ and PPAR $\gamma$ in apoptosis and proliferation of human hepatocarcinoma HepG2 cells. Cell Biochem Funct. 2010; 28: 571-7.

9. Grau R, Punzón C, Fresno M, Iñiguez MA. Peroxisomeproliferator-activated receptor alpha agonists inhibit cyclo-oxygenase 2 and vascular endothelial growth factor transcriptional activation in human colorectal carcinoma cells via inhibition of activator protein-1. Biochem J. 2006; 395: 81-8.

10. Yokoyama Y, Xin B, Shigeto T, Umemoto M, KasaiSakamoto A, Futagami M, Tsuchida S, Al-Mulla F, Mizunuma H. Clofibric acid, a peroxisome proliferatoractivated receptor alpha ligand, inhibits growth of human ovarian cancer. Mol Cancer Ther. 2007; 6: 1379-86.

11. Yamasaki D, Kawabe N, Nakamura H, Tachibana K, Ishimoto K, Tanaka T, Aburatani H, Sakai J, Hamakubo T, Kodama T, Doi T. Fenofibrate suppresses growth of the human hepatocellular carcinoma cell via PPAR $\alpha$ independent mechanisms. Eur J Cell Biol. 2011; 90: 657-64.

12. Pozzi A, Ibanez MR, Gatica AE, Yang S, Wei S, Mei S. Falck JR, Capdevila JH. Capdevila JH. Peroxisomal proliferator-activated receptor-alpha-dependent inhibition of endothelial cell proliferation and tumorigenesis. J Biol Chem. 2007; 282: 17685-95.

13. Ip E, Farrell GC, Robertson G, Hall P, Kirsch R, Leclercq I. Central role of PPARalpha-dependent hepatic lipid turnover in dietary steatohepatitis in mice. Hepatology. 2003; 38: 123-32.

14. Teoh NC, Williams J, Hartley J, Yu J, McCuskey RS, Farrell GC. Short-term therapy with peroxisome proliferation-activator receptor-alpha agonist Wy-14,643 protects murine fatty liver against ischemia-reperfusion injury. Hepatology. 2010; 51: 996-1006.

15. Reddy JK, Rao S, Moody DE. Hepatocellular carcinomas in acatalasemic mice treated with nafenopin, a hypolipidemic peroxisome proliferator. Cancer Res. 1976; 36: 1211-7.

16. Yu J, Shen B, Chu ES, Teoh N, Cheung KF, Wu CW, Wang S, Lam CN, Feng H, Zhao J, Cheng AS, To KF, Chan HL, et al. Inhibitory role of peroxisome proliferator-activated receptor gamma in hepatocarcinogenesis in mice and in vitro. Hepatology. 2010; 51: 2008-19.

17. Delerive P, De Bosscher K, Besnard S, Vanden Berghe W, Peters JM, Gonzalez FJ, Fruchart JC, Tedgui A, Haegeman G, Staels B. Peroxisome proliferator-activated receptor alpha negatively regulates the vascular inflammatory gene response by negative cross-talk with transcription factors NF-kappaB and AP-1. J Biol Chem. 1999; 274: 32048-54.

18. Zhou J, Zhang S, Xue J, Avery J, Wu J, Lind SE, Ding WQ. Activation of peroxisome proliferator-activated receptor $\alpha$ (PPAR $\alpha$ ) suppresses hypoxia-inducible factor-1 $\alpha$ (HIF-1 $\alpha$ ) signaling in cancer cells. J Biol Chem. 2012; 287: 35161-9.

19. Maggiora M, Oraldi M, Muzio G, Canuto RA. Involvement of PPAR $\alpha$ and PPAR $\gamma$ in apoptosis and proliferation of human hepatocarcinoma HepG2 cells. Cell Biochem Funct. 2010; 28: 571-7.

20. Kudo M. Signaling pathway and molecular-targeted therapy for hepatocellular carcinoma. Dig Dis. 2011; 29: 289-302.

21. Villanueva A, Newell P, Chiang DY, Friedman SL, Llovet JM. Genomics and signaling pathways in hepatocellular carcinoma. Semin Liver Dis. 2007; 27: 55-76.

22. Whittaker S, Marais R, Zhu AX. The role of signaling pathways in the development and treatment of hepatocellular carcinoma. Oncogene. 2010; 29: 4989-5005.

23. Maeda S, Kamata H, Luo JL, Leffert H, Karin M. IKKbeta couples hepatocyte death to cytokine-driven compensatory proliferation that promotes chemical hepatocarcinogenesis. Cell. 2005; 121: 977-90.

24. Arsura M, Cavin LG. Nuclear factor-kappaB and liver carcinogenesis. Cancer Lett. 2005; 229: 157-69.

25. Maeda S. NF- $\kappa B$, JNK, and TLR Signaling Pathways in Hepatocarcinogenesis. Gastroenterol Res Pract. 2010; 2010: 367694.

26. Delerive P, Gervois P, Fruchart JC, Staels B. Induction of IkappaBalpha expression as a mechanism contributing to the anti-inflammatory activities of peroxisome proliferatoractivated receptor-alpha activators. J Biol Chem. 2000; 275 : 36703-7.

27. Delerive P, De Bosscher K, Vanden Berghe W, Fruchart JC, Haegeman G, Staels B. DNA binding-independent induction of IkappaBalpha gene transcription by PPARalpha. Mol Endocrinol. 2002; 16: 1029-39.

28. Buroker NE, Barboza J, Huang JY. The IkappaBalpha gene is a peroxisome proliferator-activated receptor cardiac target gene. FEBS J. 2009; 276: 3247-55.

29. Catz SD, Johnson JL. Transcriptional regulation of bcl-2 by nuclear factor kappa B and its significance in prostate cancer. Oncogene. 2001; 20: 7342-51.

30. Poynter ME, Daynes RA. Peroxisome proliferator-activated receptor alpha activation modulates cellular redox status, represses nuclear factor-kappaB signaling, and reduces inflammatory cytokine production in aging. J Biol Chem. 1998; 273: 32833-41.

31. Hashimoto K, Kamijo Y, Nakajima T, Harada M, Higuchi M, Ehara T, Shigematsu H, Aoyama T. PPAR $\alpha$ Activation Protects against Anti-Thyl Nephritis by Suppressing Glomerular NF-кB Signaling. PPAR Res. 2012; 2012: 976089. 